\title{
Epidemiological characteristics of Dementia-related mortality in Mexico between 2012 and 2016
}

\author{
Reinhard Janssen-Aguilar, Roger A. Erosa-Villarreal, Luis A. González-Maldonado, \\ Nina I. Méndez-Domínguez*, and Martín J. Inurreta-Díaz \\ Department of Medicine, School of Health Sciences, Marist University of Merida, Mérida. Yucatán, Mexico
}

\begin{abstract}
Introduction: Dementia refers to a group of neurodegenerative disorders characterized by progressive deterioration of cognitive skills and is one of the main pathologies associated with disability and dependency among older adults. Objective: The objective of the study was to analyze the relationship between the demographic factors and mortality from dementia in the Mexican population. Methods: This was a population-based, retrospective, and cross-sectional study. We employed an open-access national dementia-related mortality dataset. Results: The overall mortality rate in Mexico was $0.16 / 1000$ inhabitants. The mean age of mortality was $84.37 \pm 0.10$ years. In the statistical analysis, sociodemographic variables that were associated with greater mortality due to dementia were age $>80$ (OR 2.91, $p<0.001)$, single $(O R$ 1.66, $p<0.001)$, female (OR 1.53, $p<0.001$ ), an urban area (OR 1.42, $p<0.001)$, to have higher education (OR 1.23, $p=0.001)$, and residency in large cities (OR 1.33, $p<0.001)$. Conclusions: Mortality from dementia arises as a cosmopolitan phenomenon associated with socioeconomic factors.
\end{abstract}

Key words: Dementia. Epidemiology. Mortality. Aged.

\section{Características epidemiológicas de la mortalidad por demencia en México durante los años 2012-2016}

\section{Resumen}

Introducción: La demencia se refiere a un grupo de trastornos neurodegenerativos caracterizados por un deterioro progresivo de las habilidades cognitivas y es una de las principales patologías asociadas con la discapacidad y la dependencia entre los adultos mayores. Objetivo: Analizar la relación entre los factores demográficos y la mortalidad por demencia en la población Mexicana. Métodos: Estudio poblacional, retrospectivo, transversal. Se empleó un conjunto de datos nacionales de mortalidad asociada a la demencia de acceso abierto. Resultados: La tasa de mortalidad general en México fue de 0.16 por cada 1000 habitantes. La edad media de mortalidad fue de $84.37 \pm 0.10$ años. En el análisis estadístico, las variables sociodemográficas que se asociaron con una mayor mortalidad por demencia fueron: edad $>80(0 R 2.91, p<0.001)$,

\section{Correspondence:}

*Nina Isabel Méndez-Domínguez

Periférico Norte, Tablaje catastral 13941

Carretera Mérida-Progreso

Date of reception: 26-11-2018

Date of acceptance: 30-04-2019

E-mail: ninuxka@ hotmail.com

DOI: 10.24875/RMN. 19000003
Available online: $30-10-2019$ Rev Mex Neuroci. 2019;20(5):222-228 www.revmexneurociencia.com 1665-5044/@ 2019. Academia Mexicana de Neurología A.C. Published by Permanyer México. This is an Open Access article under the terms of the CC BY-NC-ND license (http://creativecommons.org/licenses/by-nc-nd/4.0/). 
solteros (OR 1.66, $p<0.001)$, mujeres (OR 1.53, $p<0.001$ ), área urbana (OR 1.42, $p<0.001$, tener educación superior (OR 1.23, $p=0.001$ ), residir en ciudades grandes (OR 1.33, $p<0.001)$. Conclusiones: La mortalidad por demencia surge como un fenómeno cosmopolita asociado a factores socioeconómicos.

Palabras clave: Demencia. Epidemiología. Mortalidad. Adulto mayor.

\section{Introduction}

The aging of the population worldwide is a process without precedents in human history provoking an increase in the prevalence of chronic illnesses ${ }^{1}$. In Mexico, aging is a phenomenon that has emerged and is progressively advancing in a non-homogenous way within different federative entities ${ }^{2}$. The population pyramid of the country in the year 2015 was reported to have widened at the center and reduced at the base; moreover, the population of age 15 years or less represents $27 \%$ of the total population; in comparison, persons of age $15-65$ years constitute $65 \%$ of the total population ${ }^{3}$.

According to the National Population Council (Consejo Nacional de Población, CONAPO), it is estimated that by 2030 the aged population will constitute $14.9 \%$ of the total population; therefore, it will be considered as a population transition, and by 2050 it will be an aged population with $24.7 \%$ of the elder. This population-based phenomenon comes as a result of the increasing number of patients with chronic degenerative diseases posing new health-care challenges.

Dementia refers to a group of neurodegenerative disorders characterized by a progressive deterioration in cognitive abilities, such as memory and reasoning, and dysfunction in the ability to live independently among those affected ${ }^{4}$. The most representative causes of dementia include Alzheimer's disease (50-60\%), vascular dementia, Lewy body dementia, and frontal-temporal degeneration ${ }^{5}$.

In 2013, it was estimated that 44 million people were suffering from dementia worldwide, with 7.6 million new cases annually. It is believed that the number of people with dementia will double every 20 years reaching 76 million by 2030 and 135 million by 2050 worldwide, this increase will be more marked in developing regions than in developed regions ${ }^{5}$. Mexico has experienced a continuous increase in life expectancy having as a consequence a proportional increase of geriatric population, for that reason, dementia prevalence might also be rising. At present, there are some clinical reports estimating that of $500-700$ thousand people with dementia, approximately $25 \%$ have not been diagnosed 6 .

Dementia, stroke, and depression are considered to be illnesses that affect the brain and mental health; thus they constitute the main contributors to disability and dependence among older adults. However, these conditions receive less priority than cardiovascular illnesses and cancer, which have an earlier impact on mortality ${ }^{5}$. This pathology increases the risk of mortality among the general population. There are several sociodemographic factors that have been related to the increased risk of mortality due to dementia, such as gender, age, level of education, civil status, ethnic group, geographic location, and temporality $1,7-10$.

In Mexico, there is little, if any, information available about the sociodemographic factors most frequently associated with mortality due to dementia; for this reason, the objective of the present study is to analyze the relationship between the sociodemographic factors and the mortality due to dementia in the Mexican population during the period between 2012 and 2016 .

\section{Materials and methods}

An observational retrospective cross-sectional study was conducted. The mortality data were obtained from the national mortality database provided by the National Institute of Statistical Geography (Instituto Nacional de Geografía y Estadística, INEGI) from 2012 to 2016, which derives from the General Direction of Health Information that in a stage by stage collection and verification process registers the information from the death certificates nationwide with validation from the epidemiology department. Patients older than 65 years with a diagnosis of dementia as the cause of the death $(n=6499)$ were selected from each database per year. Cases of dementia were included for the present study based on the International Disease Codes, tenth revision that pertains to ICD-10 codes F000-F0X3. The rate of mortality due to dementia at the national level and by the state was calculated by taking the number of dementia cases and dividing them by the mid-year number of inhabitants. The population size and inhabitant numbers were obtained from the population projections issued by the CONAPO, the result of the division was subsequently multiplied by 1000 to obtain the mortality rates per 1000 inhabitants $^{3}$. To carry out a comparative statistical analysis, each dementia-related 
mortality case was paired with a randomly selected, non-dementia related mortality case. The sociodemographic variables that were evaluated included: age, gender, indigenous language, marital status, schooling, current profession, area of residence (rural, urban), affiliation, medical insurance, month of occurrence, and the population size of inhabitancy. The age was transformed as a continuous variable calculated by subtracting the date of birth from the date of death and dividing the result by 365.25 . Indigenous ethnicity, marital status (with or without couple), schooling (equal to or more than high school or less than high school level), current occupation, area of residence (rural or urban), and entitlement were coded as present or absent dichotomous variables. The month of occurrence refers to the month in which death occurred. The size of the locality refers to the number of people that inhabit the place where the death occurred ${ }^{11}$.

\section{Statistical analysis}

The descriptive statistics including the totals, proportions, and frequencies were obtained from the categorical and ratio variables. In addition, the central tendency and dispersion measures were obtained from the numerical variables. Statistical significance was evaluated through statistical hypothesis tests, by comparing proportion for nominal variables (Chi-squared) and mean-comparison tests for numerical data (student's t-test). Subsequently, logistic regression modeling was performed when dependent variables were binary, and odds ratio (OR) was calculated ${ }^{12}$. All the statistical analyses were conducted using the program Stata $14^{\circledR}$, values with $p<0.05$ were taken as statistically significant.

\section{Results}

Between 2012 and 2016; 6192 deaths due to dementia were recorded in Mexico among population over 65 years. Figure 1 displays the dementia-related mortality rate per 1000 inhabitants, per year among $\geq$ 65 years during the period 2012-2016. The total death rate in Mexico during the same period was $0.16 / 1000$ habitants. Figure 2 displays the population of the country per year during the same period. Moreover, this figure indicates that there was a considerable increase in the population of persons aged 65 years or more each year, unlike the death rate due to dementia, which was constant except for a small increase in the year 2015. In the entity analysis, it was observed that the

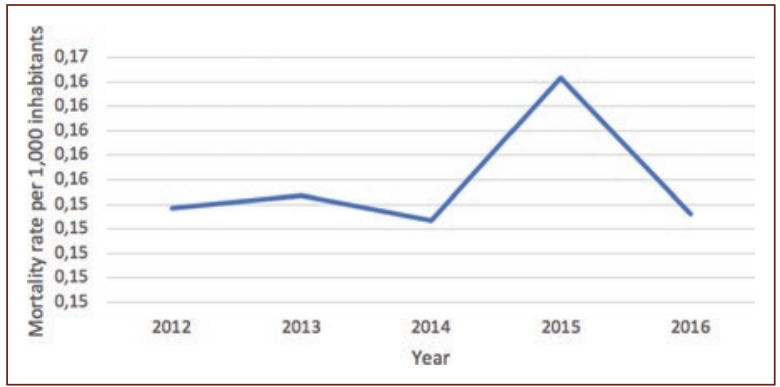

Figure 1. National rate of mortality due to dementia 2012-2016.

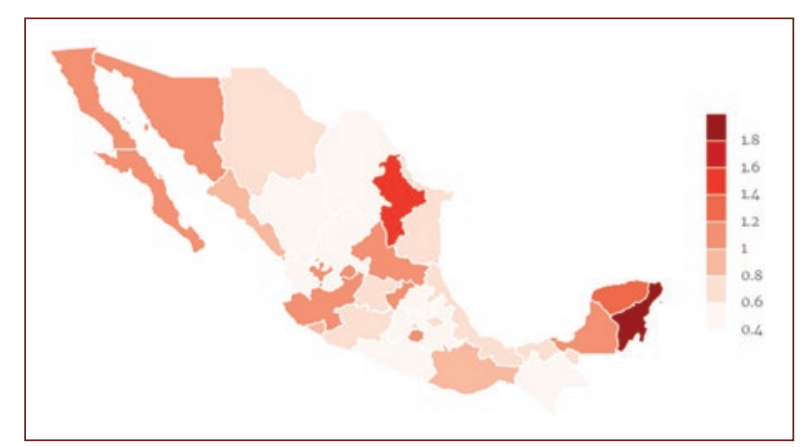

Figure 2. Incidence rate of dementia-related mortality per 1,000 inhabitants in Mexico, bewteen 2012-2016.

states Nuevo León, Quintana Roo and Yucat'n occupy the first three places in death rate in descending order (Fig. 2 and Table 1).

The sociodemographic characteristics related to deaths due to dementia are displayed in Table 1. The average age of the population living with dementia was observed to be $84.37 \pm 0.10$ years which is significantly different from those whose established cause of death was not due to dementia ( $79.32 \pm 0.12$ years).

Nearly $27.13 \%$ of dementia-related cases were found to be within the age range of $65-79$ years, $70.62 \%$ within the age range of $80-99$, and $2.24 \%$ were older than 100 years. The proportion of the population with dementia differed by gender; it was observed that dementia was more prevalent in female $(60.47 \%)$ compared to male (39.53\%).

Mortality due to dementia predominates in economically active people $(84.71 \%)$ at the time of death, with any grade of education $(73.79 \%)$, specifically less than bachelor degree $(88.55 \%)$, with entitlement $(80.12 \%)$, and medical care $(80.19 \%)$ at the time of death, living among populations < 500,000 people $(61.51 \%)$ and living in urban areas (81.72\%). $8.75 \%$ of 
Table 1. Sociodemographic characteristics of the population $n=12384$

\begin{tabular}{|c|c|c|c|c|c|}
\hline \multirow[t]{2}{*}{ Variable } & \multicolumn{2}{|c|}{ Dementia $n=6192$} & \multicolumn{2}{|c|}{ Without dementia $n=6192$} & \multirow[t]{2}{*}{$\mathrm{p}<0.05$} \\
\hline & Proportion (n) & Mean \pm SD & Proportion (n) & Mean \pm SD & \\
\hline Age & & $84.37 \pm 0.10$ & & $79.32 \pm 0.12$ & $<0.001$ \\
\hline Population $>500$ thousand & 38.49 (2383) & & 31.94 (1978) & & $<0.001$ \\
\hline Population $<500$ thousand & $61.51(3809)$ & & $68.06(4214)$ & & $<0.001$ \\
\hline Male & $39.53(2448)$ & & 50.05 (3099) & & $<0.001$ \\
\hline Female & $60.47(3744)$ & & 49.95 (3093) & & $<0.001$ \\
\hline Economically active & 84.71 (4979) & & $85.31(5031)$ & & 0.355 \\
\hline Not economically active & $15.29(672)$ & & $14.69(866)$ & & 0.355 \\
\hline Education & 73.79 (4331) & & $69.53(4070)$ & & $<0.001$ \\
\hline$\geq$ High school & $11.45(672)$ & & $9.53(558)$ & & 0.004 \\
\hline$<$ High school & $88.55(5197)$ & & 90.47 (3323) & & 0.004 \\
\hline With partner & $32.64(1970)$ & & $44.64(2680)$ & & $<0.001$ \\
\hline Without couple instead of partner & $67.36(4065)$ & & $55.48(3435)$ & & $<0.001$ \\
\hline Medical insurance & 89.19 (5272) & & $88.50(5152)$ & & 0.308 \\
\hline Without medical insurance & $80.12(4522)$ & & $80.41(4541)$ & & 0.695 \\
\hline Urban area & $81.72(5034)$ & & 75.90 (4659) & & $<0.001$ \\
\hline Rural area & $18.28(1126)$ & & 24.10 (1479) & & $<0.001$ \\
\hline Indigenous ethnicity & $8.75(463)$ & & $11.41(602)$ & & $<0.001$ \\
\hline $65-79$ years & $27.13(1680)$ & & 53.18 (3293) & & $<0.001$ \\
\hline $80-99$ years & $70.62(4373)$ & & 45.20 (2799) & & $<0.001$ \\
\hline$>100$ years & 2.24 (139) & & $1.51(100)$ & & 0.005 \\
\hline
\end{tabular}

SD: standard deviation.

the population belonged to an indigenous ethnicity at the time of death.

In the logistic regression analysis of binary dependent variables (Table 2), the sociodemographic characteristics that were directly associated with greater mortality due to dementia were: age $>80$ years (OR 2.91, $p<0.001$ ), (please note that age older than 100 years showed OR 1.40, $p=0.011$ ), single-living (OR 1.66, $p<0.001$ ), being female (OR 1.53, $p<0.001$ ), living in an urban area (OR 1.42, $p<0.001)$, and some degree of education (OR 1.23, $p<0.001$ ). In contrast, the results of the descriptive analysis demonstrated that greater education or equal to high school level was associated with a higher mortality due to dementia (OR 1.23, $p=0.001$ ), similarly, living in an area with a population $>500$ thousand people was associated with higher mortality ( $O R$ 1.23, $p=0.001)$. Medical care affiliation and having entitlement were not associated with mortality due to dementia. Living in an area with $<500,000$ people (OR 0.75, $p<0.001$ ), a level of education less than high school (OR 0.81, $p=0.001$ ), speaking an indigenous language (OR $0.741, p<0.001$ ), living in a rural area (OR $0.70, p<0.001)$, male gender (OR 0.65, $p<0.001$ ), and age between 65 and 79 years (OR 30, $p<0.001$ ) were associated with lower mortality risk due to dementia having an occupation or not was not associated with greater mortality due to dementia.

\section{Discussion}

In this study, different sociodemographic characteristics were observed to be associated with mortality due to dementia in the Mexican population aged 65 and above during the years 2012-2016. According to a 
Table 2. Logistic regression model

\begin{tabular}{|l|c|c|}
\hline Variable & OR & $\mathbf{p}<0.05$ \\
\hline Population $>500$ thousand & 1.33 & $<0.001$ \\
\hline Population $<500$ thousand & 0.75 & $<0.001$ \\
\hline Age & 1.07 & $<0.001$ \\
\hline Economically active & 0.95 & 0.355 \\
\hline Not economically active & 1.05 & 0.355 \\
\hline Education & 1.23 & $<0.001$ \\
\hline$<$ High school & 0.81 & 0.001 \\
\hline$\geq$ High school & 1.23 & 0.001 \\
\hline With partner & 0.60 & $<0.001$ \\
\hline Without partner & 1.66 & $<0.001$ \\
\hline Medical care & 1.06 & 0.308 \\
\hline Insurance & 0.98 & 0.695 \\
\hline Urban area & 1.42 & $<0.001$ \\
\hline Rural area & 0.70 & $<0.001$ \\
\hline Indigenous ethnicity & 0.74 & $<0.001$ \\
\hline Male & 0.65 & $<0.001$ \\
\hline Female & 1.53 & $<0.001$ \\
\hline $65-79$ years & 0.33 & $<0.001$ \\
\hline $80-99$ years & 2.91 & $<0.001$ \\
\hline$>100$ years & 1.40 & 0.011 \\
\hline odds & & \\
\hline
\end{tabular}

OR: odds ratio.

meta-analysis of 157 epidemiological studies carried out between 1980 and 2009 around the world, the prevalence of dementia, depending on the geographical zone, lies between 5 and $8 \%$ of adults older than 60 years. Moreover, a pattern of exponential growth in the number of dementia cases is observed with increasing age, approximately doubling every 5 years, and predominates among females ${ }^{1}$.

In our study, the age range that was associated with greater mortality was $80-99$ years (OR 2.91, $p<0.001$ ). The proportion of the population characterized by extreme old age is growing rapidly. According to Kravitz et al., the presence of dementia in this group is estimated between 50 and $60 \%$, probably due to the accumulation of preventable risk factors associated with increased age ${ }^{13}$. In general, age is a risk factor for the development of cognitive and physical pathologies and compromises individual function; in the extremely old population, this is accentuated and they are affected by multiple morbidities or at least two chronic degenerative illnesses ${ }^{14}$.

The most frequently occurring pathologies in this age group include depression, frailty syndrome, osteoporosis, diabetes, osteoarthritis, chronic renal disease, cancer, and cardiovascular diseases; dementia can contribute to the poor treatment of these comorbidities, leading to a fatal outcome $\mathrm{e}^{14,15}$.

The prevalence of sensory changes in this population increases considerably, in adults older than 85 years it is estimated that the prevalence of auditory deficiency is approximately $70-90 \%$ and visual deficiency is $23 \%$, a diagnosis of dementia could potentially cause an increase in mortality within this group ${ }^{16}$.

Similar results, with respect to mortality in this aged population, can be observed in a cohort study conducted by Martín et al. It was found that an age $>84$ years was a predictor of mortality in a Spanish population of 75 years or older hospitalized with dementia $(n=195)^{15}$. It can be inferred that dementia increases the risk of complications associated with the general characteristics of the extreme old age group, limiting their ability to self-care, increasing the likelihood of institutionalization, and hospitalization; in addition to, complications associated with chronic degenerative diseases, which could increase mortality.

Being a woman was strongly associated with mortality due to dementia with an OR of $1.53(p<0.001)$. In comparison, male gender was observed to be protective in this population (OR $0.65, p<0.001)$. Conversely, Garcia-Ptacek et al. conducted a study in a Swedish population and reported that male sex is associated with greater mortality due to dementia ${ }^{16}$. The results obtained in the present study can be attributed to the greater life expectancy of women within the Mexican population, which is associated with other risk factors of mortality due to dementia such as reaching older age and living alone without a partner ${ }^{16}$.

In relation to the socioeconomic level, Van de Vorst et al. conducted a cohort study of 15,558 participants during the years 2000-2010, the main result obtained indicated that a lower socioeconomic level is associated with greater risk of death in both men and women with dementia ${ }^{17}$. In contrast to previously reported studies, low income was not associated with odds of mortality related dementia. In the present study, dementia-related mortality was mainly linked to otherwise favorable sociodemographic characteristics, whereby a higher socioeconomic level increased the probability of dementia-related deaths. 
Interestingly, it was observed that having a level of education greater than high school was associated with higher mortality compared to a lower education level (OR 1.23 vs. $0.83 p=0.001$ ). Contador et al. conducted a study on a sample of Spanish patients diagnosed with dementia $(n=306)$ and observed that a more rapid decline in cognition was associated with greater academic achievement. Subsequently, Contador et al. conducted a cohort study of the Spanish population living with dementia $(n=269)$ and found a direct relationship between the level of education and mortality due to dementia ${ }^{18}$. This association between the level of education and mortality due to dementia could be related to the ability to carry out a greater number of complex tasks; when a clinical diagnosis has been established, it is assumed that the patient with greater academic attainment can directly perceive the impact of the spectrum of symptoms on their daily activities, such as increasing frailty, depression, and among other geriatric symptoms, which increases the probability of a fatal outcome. In light of this observation, there exist only a few studies that address this association, yet it is necessary to establish causality.

The association between the development of dementia and being single (without partner), has been addressed in multiple articles; for instance, in a systematic review and meta-analysis of 15 observation studies with a total of 812,047 participants, Sommerlad et al. (2018) observed that single participants and widowers had a relatively greater risk of developing dementia in comparison with married couples (with partner) ${ }^{19}$. Many studies have consistently demonstrated higher mortality in elderly persons living without a partner that has a diagnosis of dementia. The results of this study demonstrate that being single is associated with higher mortality (OR 1.66 vs. $0.6, p<0.001$ ); in addition, Lewis et al. observed similar results in a British population $(n=4684)$, with an increased risk of mortality in this population group. In contrast, there is evidence that in the general population couples (with partner) live longer ${ }^{8}$. Among possible explanations for this increase in mortality, it is plausible that social support is better with a partner than without since couples tend to share healthy habits and are more likely to use health support services. Likewise, frequent social interaction could contribute to a slower progression of dementia-related symptoms ${ }^{8}$. The family also has an extremely important role as primary caregivers of the person with dementia; according to Kourakos (2016) et al., the family environment may delay the onset of symptoms and the need for a professional caregiver ${ }^{14,19}$.

The present study also identified an effect of the person with dementia inhabiting either rural or urban zones, it was observed that those individuals living in an urban zone (OR 1.42, $\mathrm{p}<0.001)$ and within a population > 500,000 inhabitants (OR 1.33, p < 0.001) exhibited higher rates of mortality due to dementia compared to those living in rural zones (OR 0.7, $p<0.001)$ and within a population $<500,000$ inhabitants (OR 0.75, $p<0.001)$. In another study conducted on the population of the Republic of Congo in adults older than 65 years diagnosed with dementia $(n=2000)$, it was found that living in an urban zone is strongly associated with mortality due to dementia ${ }^{20}$. It has been observed that social support and health care differ between urban and rural zones; for instance, in a longitudinal cohort study of a Swedish population, Roheger et al. (2018) assessed mortality of patients with dementia that reside in nursing homes and observed that those that live in urban zones were more likely to be hospitalized at the time of diagnosis. However, no difference in mortality was identified ${ }^{21}$.

The identification of sociodemographic factors that increase mortality in older adult populations living with dementia is important within context, as reported by Gutiérrez et al. At present, in Mexico, there are more than 13 million adults older than 60 years experiencing their quality of life and independence being threatened by disability which is secondary to dementia ${ }^{22}$. According to the results of the dementia investigation group of Alzheimer's disease international 10/66, the incidence of this pathology in Mexico was $16.9 / 1000$ people/year in an urban region and 34.2/1000 people/year within a rural region, these high figures will continue to rise due to the epidemiological transition that the country is experiencing, it is estimated that there will be 3.5 million affected by dementia by 2050 .

In Mexico, the cost of caring for a person with dementia has risen to a total of 6157 dollars per capita ${ }^{23}$. Dementia is an undervalued pathology since it can increase the morbidity and mortality of other pathologies present before diagnosis. Considering the economic impact, disability, progressive deterioration, the impact on caregivers and the family; in addition to contributing to an increase in mortality in the elderly population, it is mandatory to establish prevention strategies, a plan of action, with public health policies focused on the reduction of modifiable factors that increase the incidence and mortality due to dementia ${ }^{23}$.

In this study, the mortality due to dementia was found to be mainly associated with women between 80 and 99 years, inhabiting an urban zone with a population of more than 500,000 inhabitants, being educated beyond high school level and living alone without a partner. 
These results suggest that the mortality due to dementia in Mexico is partly a cosmopolitan phenomenon, associated with otherwise favourable socioeconomic conditions and, with this, guides the implementation of strategies that not only permit a longer life expectancy but also a higher quality of life, free of the manifestations of dementia.

As any other study, the present one has certain limitations that need to be considered. All of the information used in this article was obtained from the national mortality registry, which is based on the information contained in death certificates (available from INEGI) that might not be always completed by a medical practitioner. The basic cause of mortality in all cases that were included for the purposes of the present study was dementia; nevertheless, there is a possibility that if dementia was not correctly diagnosed (as when the death certificate was not elaborated by a medical doctor) as the basic cause of death, patients' basic cause of death might have been mistaken with the direct cause of death which could include death by respiratory tract infections or aspiration due to swallowing impairment derived from dementia.

\section{Conflicts of interest}

None.

\section{Funding}

None.

\section{References}

1. Garre-Olmo J. Epidemiology of Alzheimer's disease and other dementias. Rev Neurol. 2018;66:377-86.

2. González K. Envejecimiento Demográfico en México: análisis Comparativo Entre las Entidades Federativas. México: la Situación Demográfica de México; 2015. p. 113-29. [Last accessed on 2018 Nov 11].

3. Consejo Nacional de Población. Proyecciones de la Población 2010-2050. Available from: http://www.conapo.gob.mx/ES/CONAPO/PROYECCIONES.

4. Xu W, Wu C. Detecting spatiotemporal clusters of dementia mortality in the United States, 2000-2010. Spat Spatiotemporal Epidemiol. 2018;27:11-20.
5. Rodríguez JL, Herrera RF. Demencias y enfeoredad de Alzheimer en América latina y el caribe. Rev Cub Salud Publica 2014;40:378-87. Available from: http://www.medigraphic.com/cgi-bin/new/resumen.cgi?IDARTICULO $=51368$

6. Guerchet M, Prina M, Prince M. Policy Brief for Heads of Government: the Global Impact of Dementia 2013-2050; 2013. Available from: https:// www.alz.co.uk/research/GloballmpactDementia2013.pdf.

7. Navarro-Gil P, González-Vélez AE, Ayala A, Martín-García S, Martínez-Martín P, Forjaz MJ, et al. Which factors are associated with mortality in institutionalized older adults with dementia? Arch Gerontol Geriatr. 2014;59:522-7.

8. Lewis G, Werbeloff N, Hayes JF, Howard R, Osborn DP. Diagnosed depression and sociodemographic factors as predictors of mortality in patients with dementia. Br J Psychiatry. 2018;213:471-6.

9. Gillum RF, Yorrick R, Obisesan TO. Population surveillance of dementia mortality. Int J Environ Res Public Health. 2011;8:1244-57.

10. Contador I, Stern Y, Bermejo-Pareja F, Sanchez-Ferro A, Benito-Leon J. Is educational attainment associated with increased risk of mortality in people with dementia? A population-based study. Curr Alzheimer Res. 2017:14:571-6.

11. INEGI. Estadística de Defunciones Generales: descripción de la Base de Datos Nacional. México: Instituto Nacional de Geografía y Estadística; 2016.

12. Juul S. An Introduction to Stata for Health Researchers. College Station, TX: Stata Press; 2006.

13. Kravitz E, Schmeidler J, Beeri MS. Cognitive decline and dementia in the oldest-old. Rambam Maimonides Med J. 2012;3:e0026.

14. Giulioli $\mathrm{C}$, Amieva H. Epidemiology of cognitive aging in the oldest old. Rev Invest Clin. 2016;68:33-9.

15. Martín J, Padierna A, Anton-Ladislao A, Moro I, Quintana JM. Predictors of mortality during hospitalization and 3 months after discharge in elderly people with and without dementia. Aging Ment Health. 2018:1-9.

16. Garcia-Ptacek $S$, Farahmand $B$, Kåreholt I, Religa $D$, Cuadrado $M L$, Eriksdotter M, et al. Mortality risk after dementia diagnosis by dementia type and underlying factors: a cohort of 15,209 patients based on the swedish dementia registry. J Alzheimers Dis. 2014;41:467-77.

17. van de Vorst IE, Koek HL, Stein CE, Bots ML and Vaartjes I. Socioeconomic Disparities and Mortality After a Diagnosis of Dementia: Results From a Nationwide Registry Linkage Study. Am J Epidemiol. 2016;184:219-26.

18. Contador I, Bermejo-Pareja F, Pablos DL, Villarejo A, Benito-León J. High education accelerates cognitive decline in dementia: a brief report from the population-based NEDICES cohort. Dement Neuropsychol. 2017; 11:297-300

19. Sommerlad A, Ruegger J, Singh-Manoux A, Lewis G, Livingston G Marriage and risk of dementia: systematic review and meta-analysis of observational studies. J Neurol Neurosurg Psychiatry. 2018;89:231-8. Available from: https://jnnp.bmj.com/content/89/3/231.

20. Kourakos M, Kafkia T, Minasidou E. Social support and care for patients with Alzheimer's disease in the community. Int J Caring Sci. 2016;9:1186. Available from: http://www.internationaljournalofcaringsciences.org/ docs/51 kourakos review 93 a pdf.

21. Samba $\bar{H}$, Guerchet $M$, Ndamba-Bandzouzi $B$, Mbelesso $P$, Lacroix $P$, Dartigues JF, et al. Dementia-associated mortality and its predictors among older adults in Sub-Saharan Africa: results from a 2-year follow-up in congo (the EPIDEMCA-FU study). Age Ageing. 2016;45:681-7.

22. Roheger M, Zupanic E, Kåreholt I, Religa D, Kalbe E, Eriksdotter M, et al. Mortality and nursing home placement of dementia patients in rural and urban areas: a cohort study from the Swedish dementia registry. Scand $\mathrm{J}$ Caring Sci. 2018;32:1308-13.

23. Gutiérrez-Robledo LM, Arrieta-Cruz I. Demencias en México: la necesidad de un Plan de Acción. Gac Med Mex. 2015;151:667-73. Available from: http:// www.medigraphic.com/cgi-bin/new/resumen.cgi?IDARTICULO=61983. 